\title{
BMJ Open Delayed discharges at a major arterial centre: a 4-month cross-sectional study at a single specialist vascular surgery ward
}

\author{
J S M Houghton, D Urriza Rodriguez, A R Weale, M J Brooks, D C Mitchell
}

To cite: Houghton JSM, Urriza Rodriguez D, Weale AR, et al. Delayed discharges at a major arterial centre: a 4-month crosssectional study at a single specialist vascular surgery ward. BMJ Open 2016;6: e011193. doi:10.1136/ bmjopen-2016-011193

- Prepublication history for this paper is available online. To view these files please visit the journal online (http://dx.doi.org/10.1136/ bmjopen-2016-011193).

Received 19 January 2016 Revised 6 August 2016 Accepted 23 August 2016

CrossMark

Major Arterial Centre, Bristol Bath Weston Vascular Network, Southmead Hospital, North Bristol NHS Trust, Bristol, UK

Correspondence to John Houghton; jsmhoughton@gmail.com

\section{ABSTRACT}

Objectives: Delayed discharges are a significant problem for the National Health Service. The objectives of this study were to determine the prevalence and impact of delayed discharge at a single specialist vascular surgery ward.

Design: A cross-sectional observational study. Setting: A single specialist vascular unit in the UK during a 4-month study period (01/09/2014-31/12/ 2014).

Participants: All patients admitted to the ward during the study period were included. Patients spending $\geq 1$ night on the ward once declared medically fit for discharge (MFFD) were prospectively identified and data prospectively collected. All other patients were identified retrospectively with data collected retrospectively from electronic records.

Outcome measures: Primary outcome was number of patients experiencing delayed discharge. Secondary outcome measures were length of stay, length of delay and cost of delay.

Results: There were 268 admissions with a total length of stay (LoS) of 2776 days. 57 admissions $(21.3 \%)$ experienced delayed discharges with a total 535 excess bed days (19.3\% total LoS) once MFFD. Unplanned admission (relative risk 7.3 (95\% Cl 2.7 to 20.0; $p<0.001)$ ) and index amputation (relative risk $9.2(95 \% \mathrm{Cl} 3.8$ to $22.0 ; p<0.001)$ ) were associated with increased risk of delayed discharge. There were significant differences in the length of delay by the reason for the delay $(p=0.01)$. Delay due to the provision of social services and inpatient rehabilitation were associated with longer length of delay (post hoc analysis). Age was not independently associated with either increased risk of delayed discharge or length of delay.

The total estimated cost of delayed discharges during the study period was £146 055 .

Conclusions: A significant number of vascular patients experience delayed discharge. MFFD vascular patients occupy a high proportion of vascular beds at considerable financial cost. Unplanned admissions, amputees and those delayed due to social services contributed most to delays. Closer integration with community health and social care providers may reduce delays.

\section{Strengths and limitations of this study}

- This study is the first in-depth analysis of delayed discharges at a UK vascular centre.

- While it is a single-centre study, the number of patients included is equivalent to or greater than previous similar studies of delayed discharges and large enough for statistical analysis.

- Data for all patients experiencing delayed discharge were prospectively collected. A full data set was collected for all patients included in the study.

- Limitations of the study include: retrospective data collection for patients with no delayed discharge, a small number of patients having admissions extending outside the study period and lack of assessment of the wider impact of delayed discharges on inpatient vascular services.

\section{INTRODUCTION}

Delayed discharges are a significant problem for the National Health Service (NHS), costing over 1 million acute bed days in England in 2014. ${ }^{1}$ Acute care beds being occupied by patients medically fit for discharge (MFFD) can have a significant impact on surgical care. This can include delays in admission of emergency patients, cancellations of elective procedures, waiting list delays and delaying the transfer of patients from critical care beds to a ward. Across the NHS in England, in 2014, there were 304376 patients spending more than 4 hours waiting in emergency departments for an inpatient bed $^{2}$ and 68745 last minute cancelled elective operations due to non-clinical reasons including lack of ward or critical care bed. ${ }^{3}$

Vascular surgery services across the UK are undergoing a significant redesign with centralisation of both elective and emergency inpatient services to major arterial centres and the creation of vascular networks. ${ }^{4}$ This has been driven by a number of studies 
showing a relationship between volume and outcomes for aortic surgery. ${ }^{5}$ Safe and efficient working of a major arterial centre (MAC) rely on the availability of specialist beds for elective operating, as well as capacity for direct admission or transfer (from non-arterial centres) of emergency vascular patients.

Owing to the high numbers of patients of advanced age, frailty, impaired mobility and complex wounds, vascular patients tend to lead to complex discharges from acute care to the community. The Vascular Society advocates transfer of care of these patients directly to the community or intermediate care setting rather than to a non-arterial centre where possible. ${ }^{6}$ Although delays in discharge are a recognised common problem in the provision of inpatient vascular services, there is a paucity of published literature on the impact this imposes on the system.

The primary objective of this study was to identify the prevalence of delayed discharge at a single specialist vascular ward. Secondary objectives included assessing the impact of delayed discharge, in terms of total length of stay (LoS) once MFFD, overall cost of excess bed days, and factors associated with both delay in discharge and length of delay.

\section{METHODS}

\section{Study design}

A cross-sectional study over 4 months (1 September 2014 to 31 December 2014) was undertaken at a single, 32 bed, specialist vascular surgery ward. All patients admitted to the ward during this period were included in the study.

All patients who had a delayed discharge were identified prospectively during the study period. Patients who remained an inpatient for one or more nights $(\geq 1$ night) after being deemed MFFD were classified as having a delayed discharge. Patients were declared MFFD at a daily (7 days a week) consultant vascular surgeon led, multidisciplinary ward round (as documented in the medical notes). Patient data collected prospectively included: age, mode of admission (planned or unplanned), date declared MFFD, date of discharge, whether the patient underwent major lower limb amputation during their admission (index amputation) and reason for delay. Reason for delay was classified as the last remaining provision required to facilitate discharge from the ward (eg, delivery of equipment to the patient's home) as determined by the multidisciplinary team (MDT) and documented in the medical notes.

All other patients admitted to the ward during the study period were identified retrospectively from coding records. Data including: date of admission, date of discharge, mode of admission and index amputation were collected retrospectively from electronic records for all patients staying on the same ward during the study period.

The primary outcome measure was number of patients experiencing delayed discharge. Secondary outcome measures included: LoS, length of delay and cost of excess bed days.

Of note, the study was undertaken during a period when the local regional vascular surgery services were reconfigured. On 13 October 2014, the unit became the MAC for a vascular network, combining three inpatient vascular units to a single site providing services for $\sim 1.3$ million people.

\section{Data analysis}

Difference in overall LoS between patients with, and without delayed discharge, was investigated using a Mann-Whitney U test. Risk factors for delayed discharge were investigated using a binary logistic regression analysis (forward stepwise conditional; probability for entry 0.05 ; probability for removal 0.10 ). The influence of factors (mode of admission, gender, age, index amputation and reason for delay) on length of delay in discharge was assessed using a univariate analysis of variance. Post hoc analysis (least significant difference test) was undertaken where appropriate. Length of delay data was $\log$ transformed to reduce the skew in the length of delay to more closely resemble a parametric data set. A one sample Kolmogorov-Smirnov test was then used to assess the data for normality of the distribution.

Statistical analysis was performed with the software package for the social sciences (V.16 for Windows, SPSS, Chicago, Illinois, USA). A $\mathrm{p}<0.05$ was considered statistically significant.

Cost analysis was based on Department of Health reference costs from 2013 of 2273 per excess bed day. ${ }^{7}$

\section{RESULTS}

There were a total of 268 inpatient events during the study. Total LoS of all patients during the study was 2776 days. A total of $181(67.5 \%)$ patients were male, $168(62.7 \%)$ admissions were unplanned and 31 $(11.6 \%)$ patients underwent index amputation. The median age was 70.5 (IQR: 60.75-80; range: 28-97). A complete data set was available for all patients included in the study.

Fifty-seven (21.3\%) inpatient episodes experienced a delayed discharge. Total LoS of patients with delayed discharges was 1163 bed days (41.9\%). The median total LoS for patients with delayed discharges was 18 days (IQR: 1127), compared to 6 days (IQR: 2-9) for those without delayed discharge $(\mathrm{p}<0.001$; Mann-Whitney $\mathrm{U}$ test $)$.

During the study, patients experiencing a delayed discharge occupied a total of 535 excess bed days once declared MFFD (19.3\% total bed days). The median length of delay in discharge was 7 days (IQR:3-13). Overall bed occupancy of patients declared MFFD during the study period was four patients per day.

\section{Factors associated with delayed discharge}

A total of $52(31.0 \%)$ unplanned admissions experienced delayed discharge, while only five $(5.0 \%)$ planned 
admissions experienced delayed discharge (table 1). The relative risk of delayed discharge for patients with unplanned admission was 7.3 (95\% CI: 2.7 to 20.0; $\mathrm{p}<0.001$; binary logistic regression analysis). Thirty-one patients underwent major lower limb amputation of which $20(62.5 \%)$ experienced delayed discharge. The relative risk of delayed discharge for patients undergoing index amputation was 9.2 (95\% CI 3.8 to 22.0; $\mathrm{p}<0.001$; binary logistic regression analysis). Neither age nor gender was independently associated with an increased risk of delayed discharge.

\section{Factors associated with length of delay}

Delays due to the provision of social services contributed most to overall delays (table 2). Seventeen inpatients (29.8\%) were delayed a total of 294 excess bed days $(55.0 \%)$ awaiting the provision of social services. Ten patients $(17.5 \%)$ suffered a delayed discharge waiting for inpatient rehabilitation bed (intermediate care) with a median delay of 9 days. Repatriation to non-arterial centres did not contribute considerably to overall delays with five patients $(8.8 \%)$ delayed 21 days $(3.9 \%)$. Twelve patients $(21.0 \%)$ had delayed discharges waiting for provision of ongoing negative pressure therapy (NPT) in the community with a median delay of 4 days. After statistical analysis, reason for delay was the only factor that had a significant association with length of delay $(\mathrm{p}=0.01$; univariate analysis of variance). On post hoc analysis (least significant difference test), delays due to provision of social services and inpatient rehabilitation were significantly associated with longer length of delay (table 3). Although length of delay in discharge appears to increase with age and is greater in patients who underwent major lower limb amputation, these were not found to be statistically significant.

\section{Cost analysis}

The total costs of accommodating patients once MFFD (at $£ 273$ per excess bed day) ${ }^{7}$ were estimated at $£ 146055$ during the study period. This would translate to an annual cost in excess of $£ 435000$ in terms of excess bed days alone (table 2).

\section{DISCUSSION}

Appropriate use of acute vascular surgery beds is increasingly important as services are reconfigured into vascular networks and MAC in the UK. Delayed discharges pose a significant imposition on the delivery of effective vascular inpatient services and have a potentially large financial impact. This study has identified that delayed discharge contributes greatly to overall $\operatorname{LoS}$ in a specialist vascular ward. Delays due to the provision of social care followed by awaiting an inpatient rehabilitation bed contribute most to excess bed days. Factors that contribute to a potentially delayed discharge include major lower limb amputation and emergency admission.

The strengths of this study include prospective data collection of patients declared MFFD, a reasonably long study period of 4 months with $>2500$ total bed days included and a large enough number of 57 patients remaining an inpatient while MFFD for detailed analysis of the causes of their delays in discharge. There were no missing data for any of the patients included. The decision as to when a patient was deemed MFFD, while subjective, was consistently made at a daily consultant-led multidisciplinary ward round.

There were limitations to this study. Initially, only patients experiencing delayed discharge were studied as part of an ongoing quality improvement project aimed at reducing the impact of delayed discharge on inpatient services at our centre. This study was retrospectively broadened to all patients admitted to the ward during the study period, to allow both calculation of impact on delayed discharge on overall LoS and limited comparison with patients who did not encounter delays in discharge. Thus, the data for patients not experiencing delayed discharge are less robust, limiting the reliability of the conclusions. The difference in median LoS of patients with delayed discharge was almost double the median delay in discharge, suggesting that they are

Table 1 Factors associated with delayed discharge in all patients

\begin{tabular}{|c|c|c|c|c|}
\hline & Overall $(\mathrm{N}=268)$ & No delay $(\mathrm{N}=211)$ & $\begin{array}{l}\text { Delayed discharge } \\
(\mathrm{N}=57)\end{array}$ & $\begin{array}{l}\text { Estimated relative risk } \\
(95 \% \mathrm{Cl})^{\star}\end{array}$ \\
\hline \multicolumn{5}{|l|}{ Gender } \\
\hline Male & $181(67.5 \%)$ & $146(69.2 \%)$ & $34(59.6 \%)$ & $0.7(0.3$ to 1.3$)(p=0.2)$ \\
\hline Female & $87(32.5 \%)$ & $65(30.8 \%)$ & $23(40.4 \%)$ & - \\
\hline Median age & 70.5 (IQR: $60.75-80)$ & 70 (IQR: 60.5-79.5) & 73 (IQR: 63-82) & $1.0(1.0$ to 1.0$)(p=0.2)$ \\
\hline \multicolumn{5}{|l|}{ Mode of admission } \\
\hline Unplanned & $168(62.7 \%)$ & $116(55.0 \%)$ & $52(91.2 \%)$ & $7.3(2.7$ to 20.0$)(p<0.001)$ \\
\hline Planned & $100(37.3 \%)$ & $95(45.0 \%)$ & $5(8.8 \%)$ & - \\
\hline \multicolumn{5}{|l|}{ Amputee? } \\
\hline Index amputation & $31(11.6 \%)$ & $11(5.2 \%)$ & $20(35.1 \%)$ & $9.2(3.8$ to 22.0$)(p<0.001)$ \\
\hline No amputation & $237(88.4 \%)$ & $200(94.8 \%)$ & $37(64.9 \%)$ & - \\
\hline
\end{tabular}


Table 2 Factors associated with length of delay in discharge in patients experiencing delayed discharge including estimated and projected annual cost per reason for delay

\begin{tabular}{|c|c|c|c|c|c|}
\hline Reason for delay & Patients (\%) & $\begin{array}{l}\text { Total delay } \\
\text { (days) (\%) }\end{array}$ & $\begin{array}{l}\text { Median delay } \\
\text { (days) (IQR) }\end{array}$ & $\begin{array}{l}\text { Est. cost (study } \\
\text { period) }(£)\end{array}$ & $\begin{array}{l}\text { Est. annual cost } \\
\text { (projected) }(£)\end{array}$ \\
\hline \multicolumn{6}{|l|}{ Type of delay $(p=0.01)$ - } \\
\hline Social & $17(29.8)$ & $294(55.0)$ & $16(12-23)$ & 80262 & 240786 \\
\hline Housing† & $3(5.3)$ & $79(14.7)$ & 23 & 21567 & 64701 \\
\hline Safeguarding & $2(3.5)$ & $30(5.6)$ & 15 & 8190 & 24570 \\
\hline Package of care & $10(17.5)$ & $143(26.5)$ & 14 & 39039 & 117117 \\
\hline Placement‡ & $2(3.5)$ & $42(7.8)$ & 21 & 11466 & 34398 \\
\hline Rehab (inpatient) & $10(17.5)$ & 99 (18.5) & $9(7-12)$ & 27027 & 81081 \\
\hline Repatriation & $5(8.8)$ & $21(3.9)$ & $5(5-5)$ & 5733 & 17199 \\
\hline Community NPT§ & $12(21.1)$ & $57(10.7)$ & $4(3-7)$ & 15561 & 46683 \\
\hline Other & $13(22.8)$ & $64(12.0)$ & $2(2-7)$ & 17472 & 52416 \\
\hline Equipment & $5(8.8)$ & $39(7.2)$ & 8 & 10647 & 31941 \\
\hline Mobility & $2(3.5)$ & $8(1.5)$ & 4 & 2184 & 6552 \\
\hline Dossette box & $2(3.5)$ & $2(0.4)$ & 2 & 546 & 1638 \\
\hline Family concern & $1(1.8)$ & $4(0.7)$ & 4 & 1092 & 3276 \\
\hline $\begin{array}{l}\text { Home OT } \\
\text { assessment }\end{array}$ & $1(1.8)$ & $2(0.4)$ & 2 & 546 & 1638 \\
\hline Home rehab & $1(1.8)$ & $2(0.4)$ & 2 & 546 & 1638 \\
\hline $\begin{array}{l}\text { Transfer to other } \\
\text { specialty }\end{array}$ & $1(1.8)$ & $7(1.3)$ & 7 & 1911 & 5733 \\
\hline \multicolumn{6}{|l|}{ Gender $(p=0.5) \emptyset$} \\
\hline Male & 34 (59.6) & 307 (57.4) & $7(2.25-12.75)$ & 83811 & 251433 \\
\hline Female & $23(40.4)$ & $228(42.6)$ & $7(4-15.5)$ & 62244 & 186732 \\
\hline \multicolumn{6}{|l|}{ Age $(p=0.6)$ ๆ } \\
\hline Age 33-64 years & $16(28.1)$ & $139(26.0)$ & $6.5(2-9.25)$ & 37947 & 113841 \\
\hline Age $65-74$ years & $13(22.8)$ & 94 (17.6) & $7(3-7)$ & 25662 & 76986 \\
\hline Age $75-81$ years & $1424.6)$ & $113(21.1)$ & $7(3.25-12)$ & 30849 & 92547 \\
\hline Age $82-94$ years & $14(24.6)$ & $189(35.3)$ & $10.5(5-18.5)$ & 51597 & 154791 \\
\hline \multicolumn{6}{|c|}{ Mode of admission $(p=0.2) \uparrow$} \\
\hline Unplanned & $52(91.2)$ & 478 & $7(3-12.25)$ & 130494 & 391482 \\
\hline Planned & $5(8.8)$ & 57 & $12(9-17)$ & 15561 & 46683 \\
\hline \multicolumn{6}{|l|}{ Amputation $(p=0.2)$ - } \\
\hline Index amputation & $20(35.1)$ & $270(50.5)$ & $12(7.75-17.5)$ & 73710 & 221130 \\
\hline No index amputation & 37 (64.9) & 265 (49.5) & $5(3-7)$ & 72345 & 217035 \\
\hline Total & $57(100)$ & $535(100)$ & $7(3-13)$ & 146055 & 438165 \\
\hline
\end{tabular}

Table 3 Summary of post hoc analysis (Least Significant Difference Test) of association of reason for delayed discharge and length of delay-numbers represent $\mathrm{p}$ values for comparison between categories

\begin{tabular}{llllll}
\hline $\begin{array}{l}\text { Reason for } \\
\text { delay }\end{array}$ & Social & Rehab* & Repat† & NPT‡ & Other \\
\hline Social & - & 1.0 & $<0.05$ & $<0.01$ & $<0.001$ \\
Rehab* & - & - & 0.5 & 0.2 & $<0.05$ \\
Repat† & - & - & - & 1.0 & 1.0 \\
NPT & - & - & - & - & 1.0 \\
\hline
\end{tabular}

*Inpatient rehabilitation.

†Repatriation to non-arterial centre.

‡Community negative pressure therapy.

NPT, negative pressure therapy. sicker, more complex patients. However, the far larger proportion of planned admissions (such as patients undergoing carotid endarterectomy or endovascular aneurysm repair who typically stay only one night in our unit) will have significantly reduced the overall median LoS of patients without delayed discharge. Clearly, the two groups of delayed and non-delayed patients are heterogeneous; however, patient data regarding presenting disease (eg, peripheral arterial disease, diabetic foot disease or aortic aneurysm) or management during admission were not collected prospectively and could not be reliably collected retrospectively. As such, no analysis of the impact of these factors on LoS, risk of delay or length of delay could be made. The study was carried 
out at a single centre limiting how generalisable the conclusions are. The study being carried out during a service reorganisation may underestimate the prevalence and impact of delayed discharge due to lower numbers of inpatients during the first month of the study prior to reconfiguration. Conversely, since the study period included Christmas when both elective operating and community health and social care provision are reduced, this may cause an overestimation of the prevalence and impact of delayed discharge. No independent verification of MFFD status or reason for delay was undertaken and was subjectively determined, potentially introducing bias and reducing how generalisable the conclusions are. However, the decision that a patient is MFFD was made by a consultant-led multidisciplinary ward round in the same consistent way across the study period, and these data were collected prospectively from patient records. No independent verification was made of reason for delayed discharge; however, this was consistently categorised as the final provision required to facilitate discharge as determined by the MDT and documented in the medical notes. There were 30 patients (including 9 with delayed discharges) who had admissions that extended prior to or beyond the study period included in the study. Only data from within the study period were included for analysis to ensure accurate calculation of excess bed days within the study period, but this may have underestimated the length of delays from some causes of delayed discharge. Furthermore, no assessment of wider indirect effects of delays in discharge, such as delays in admissions, transfers from intensive care or a network hospital, cancelled elective operating, or numbers of vascular surgery outliers, was measured during this study. Clearly, these will have financial implications for service delivery and also for the quality of care delivered to patients.

Considering the huge impact that delayed discharges have on the provision of inpatient surgical care, there is relatively little published literature on the subject. A recent systematic review including medical, surgical and psychiatric patients found that structured discharge planning potentially results in a moderate reduction in LoS and unscheduled readmission rate for older patients. However, the review identifies that effectiveness of communication with community services, impact on the overall bed usage and potential cost savings were not measured in the trials. ${ }^{8}$ Patient and admission factors associated with delayed discharge identified by our study include emergency admissions and social care provision on discharge. These findings are largely consistent with recent published articles assessing the causes for delayed discharges from acute care settings. However, while there was a tendency for older patients to have a longer length of delay in our study, age was not found to be independently associated with either increased risk of delayed discharge or length of delay. It is likely that this is due to a very small number of young patients with a considerable delay in discharge due to provision of suitable accommodation following major lower limb amputation. In our experience, it is not unusual for a vascular ward to have a small minority of patients similar to this in any given year. A recent UK based prospective study of vascular and general surgery patients found most significant delays in discharge in emergency admissions and elderly patients. ${ }^{9}$ A study looking into causes for delayed discharges from a single medical ward also found that most delays were due to social care requirements. This study noted that there was a trend of increasing delays to discharge experienced by patients of increasing age. This particular study estimated the annual cost of delayed discharges from a single ward to be over $£ 500000{ }^{10}$ similar to our estimates. A recent large study in Northern Italy similarly showed that a greater proportion of urgent admissions experienced delayed discharge, with social factors and wait for an inpatient rehabilitation bed by far the most common reasons for delay. ${ }^{11}$ Our study was also able to identify additional vascular surgery-specific factors that can potentially lead to delays in discharge. These are major lower limb amputation and, to a lesser extent, complex wounds requiring ongoing community NPT. Patients delayed waiting community NPT had all started negative pressure wound therapy during their admission and were awaiting capacity for this to be continued by community nursing teams prior to discharge. These patients typically included those undergoing minor lower limb amputation or debridement for diabetic foot disease. While these patients did not have long delays, there were a large number of patients who experienced delays due for this reason, meaning community NPT contributed to $10.7 \%$ of all excess bed days during the study period. Vascular patients, owing to their impaired mobility, advanced age, multiple comorbidities, frailty and complex wounds, tend to necessitate complex discharges. This has been evidenced in a previous study assessing surgical patients awaiting discharge once declared MFFD from acute surgical beds. It showed that there are a disproportionate number of vascular patients among this subset of patients. ${ }^{12}$ However, to the best of our knowledge, in-depth analysis of delays in discharge of vascular patients in the UK has not been published previously.

The study highlights the reliance of acute hospitals on outside health and social care providers to facilitate efficient safe discharges and handover of care within the community. With the numbers of over $65 \mathrm{~s}$ projected to rise from 11 million currently to 16 million by $2034,{ }^{13}$ the pressures on social services to provide adequate social care are only set to increase. Despite this knowledge, there has been a fall in spending on social care in England of $£ 770$ million since 2010 . $^{13}$ The number of over $65 \mathrm{~s}$ receiving social services funded home care has also fallen from 415000 to 372000 . The numbers receiving social services funded residential care and nursing home care places have also fallen from 145000 to 138000 since $2011-2012 .{ }^{14}$ In contrast, there remain a 
number of targets on acute hospitals to treat and admit patients; however, there are no targets regarding timely discharges on either acute trusts or community health and social care services. Also, there are no robust national standards or guidelines that would facilitate audit of discharge processes. Therefore, with ongoing financial constraints on social care provision in the community and the increasingly ageing population, we believe that this reliance will become more prominent. Subsequently, it will be essential for acute hospitals to develop strong links with local social and healthcare providers in the community to lessen the impact on inpatient services.

Following on from this study, we are implementing ways of improving written and verbal communication around discharge goals and planning within the MDT. This has also been extended to include outside care agencies providing ongoing health and social care in the communities the vascular network covers. We plan to undertake further research to identify, on admission, patients at risk of needing complex discharge planning and implementing interventions early to prevent subsequent predictable delays in discharge. We hope that by identifying at-risk patients early in their admission and communicating effectively within and outside the MDT, we can reduce delays in discharge and LoS. If all delays to discharge could be eradicated, based on the data in this study, it would reduce mean LoS by 2 days per admission. While this is unrealistic in the short term, even a moderate reduction in delays in discharge will have beneficial implications in terms of service delivery, costs and quality of patient care. Further research to formally assess the indirect impact of delayed discharge on vascular services is needed. We believe this would aid in the creation of national guidelines and standards to facilitate ongoing audit and standardise care provided at vascular units across the UK.

\section{Twitter Follow John Houghton at @jsmhoughton}

Contributors JSMH designed the study, undertook the data analysis. JSMH and DUR collected data and wrote the manuscript. ARW undertook the data analysis and revised the manuscript. MJB reviewed the data analysis and revised the manuscript. DCM designed the study and revised the manuscript. All authors were involved in data interpretation.

Funding Funding for open access publication was provided by departmental charitable funds.

Competing interests None declared.
Ethics approval All data were collected as part of a locally registered quality improvement project and, as such, no additional approval from a local ethics committee was required.

Provenance and peer review Not commissioned; externally peer reviewed.

Data sharing statement $A$ full data set is available on request from the corresponding author (John Houghton) at jsmhoughton@gmail.com. Consent was not obtained but the presented data are anonymised and risk of identification is low.

Open Access This is an Open Access article distributed in accordance with the Creative Commons Attribution Non Commercial (CC BY-NC 4.0) license, which permits others to distribute, remix, adapt, build upon this work noncommercially, and license their derivative works on different terms, provided the original work is properly cited and the use is non-commercial. See: http:// creativecommons.org/licenses/by-nc/4.0/

\section{REFERENCES}

1. NHS England. Delayed Transfers of Care Data 2014-15. 2015. http://www.england.nhs.uk/statistics/statistical-work-areas/ delayed-transfers-of-care/delayed-transfers-of-care-data-2014-15/

2. NHS England. A\&E Attendancs and Emergency Admissions 201415. 2015. http://www.england.nhs.uk/statistics/statistical-work-areas/ ae-waiting-times-and-activity/weekly-ae-sitreps-2014-15/

3. NHS England. Cancelled Elective Operations. 2015. http://www. england.nhs.uk/statistics/statistical-work-areas/cancelled-electiveoperations/

4. Vascular Society of Great Britain \& Ireland. The provision of services for Patients with Vascular Disease 2012. 2011. http://www.wales. nhs.uk/sitesplus/861/opendoc/187537

5. Holt PJ, Poloniecki JD, Gerrard D, et al. Meta-analysis and systematic review of the relationship between volume and outcome in abdominal aortic aneurysm surgery. Br J Surg 2007;94:395-403.

6. Vascular Society of Great Britain \& Ireland. The Provision of Services for Patients with Vascular Disease 2014. 2014. http://www. vascularsociety.org.uk/wp-content/uploads/2014/11/The-Provisionof-Services-2014.pdf

7. Department of Health. Reference costs 2012-13. 2013. https://www. gov.uk/government/uploads/system/uploads/attachment_data/file/ 261154/nhs reference costs 2012-13 acc.pdf

8. Shepperd S, Lannin NA, Clemson LM, et al. Discharge planning from hospital to home (review). Cochrane Database Syst Rev 2013; (1):CD000313

9. Majeed MU, Williams DT, Pollock R, et al. Delay in discharge and its impact on unnecessary hospital bed occupancy. BMC Health Serv Res 2012;12:410.

10. Hendy P, Patel JH, Kordbacheh T, et al. In-depth analysis of delays to patient discharge: a metropolitan teaching hospital experience. Clin Med (Lond) 2012;12:320-3.

11. Lenzi J, Mongardi M, Rucci P, et al. Sociodemographic, clinical and organisational factors associated with delayed hospital discharges: a cross-sectional study. BMC Health Serv Res 2014;14:128.

12. Benson RT, Drew JC, Galland RB. A waiting list to go home: an analysis of delayed discharges from surgical beds. Ann $R$ Coll Surg Engl 2006;88:650-2.

13. Age UK. Later life in the United Kingdom factsheet. 2015. http:// www.ageuk.org.uk/Documents/EN-GB/Factsheets/Later_Life_UK_ factsheet.pdf?dtrk=true

14. Health \& Social Care Information Centre. Community Care Statistics, Social Services Activity, England 2013-14. 2014. http://www.hscic. gov.uk/catalogue/PUB16133 